\title{
Increasing non-oil revenue potentiality through digital commerce: the case study in KSA
}

\author{
Saeed Q. Al-Khalidi Al-Maliki
}

Department of MIS, College of Business, King Khalid University, Abha, Saudi Arabia

\begin{abstract}
Purpose - This study mainly focuses on the potentiality of the e-commerce industry's opportunities and limitations in the Kingdom of Saudi Arabia (KSA) specifically toward non-oil revenue sectors.

Design/methodology/approach - E-commerce contribution to the retail market industry becomes more global and more flexible with the rapid growth of the Internet and information technology revolution. A new way of conducting business is rendered by e-commerce, which helps to make a profit electronically.

Findings - The main contributions of e-commerce are management of company operations, easy and cheaper ways of extending their markets and coordinating with the value chain across different borders. In addition, the Internet and e-commerce are responsible for removing language barriers, cultural diversification and extending the market to the national boundaries. The countries would have many innovative and dynamic aspects by the beginning of the global market that increases national revenue, market, employment opportunity, capital and access to technology and information.

Originality/value - At present, KSA's national revenue mostly depends on oil and its related commodities, while other trades compete with the global market and increase national income. So, it is essential to increase other Saudi products to reach a global business level through e-commerce. Moreover, the study suggests accessing new markets and participating in global production to improve e-commerce structure without affecting current employment patterns, industry structure, productivity and Saudi culture.
\end{abstract}

Keywords Digital commerce, Digital economy, E-commerce, Global market, Vision 2030

Paper type Research paper

\section{Introduction}

The incredible development of information and communication technology (ICT) has resulted in the rapid growth of e-commerce trade in different fields, including agriculture, finance, industry, etc. (Lin et al, 2010). Different online business-related activities (services and products) are referred to by e-commerce (Rosen, 2000; Babenko et al, 2019). Generally, it is considered as the sales aspect of selling the product through electronic through Internet and communication technology. E-commerce comprises data exchange for facilitating payments and other financial procedures. At present, the exchange of services and goods through e-commerce comprises four broad groups that are further divided into eight levels (Rosen, 2000; Babenko et al, 2019). The levels at which e-commerce exchange can be carries out include; business-to-business (B2B), business-to-consumer (B2C), business-to-government (B2G), consumer-to-business (C2B), consumer-to-consumer (C2C), government-to-business (G2B), government to consumer (G2C) and administration-to-business (A2B) (Figure 1).

(C) Saeed Q. Al-Khalidi Al-Maliki. Published in Journal of Money and Business. Published by Emerald Publishing Limited. This article is published under the Creative Commons Attribution (CC BY 4.0) licence. Anyone may reproduce, distribute, translate and create derivative works of this article (for both commercial and non-commercial purposes), subject to full attribution to the original publication and authors. The full terms of this licence may be seen at http://creativecommons.org/licences/by/4.0/ legalcode

The author is thankful to all the associated personnel who contributed to this study by any means.

Funding: The study is not funded through any source. 
$\underset{1,2}{\mathrm{JMB}}$

66

Figure 1.

Sort of e-commerce

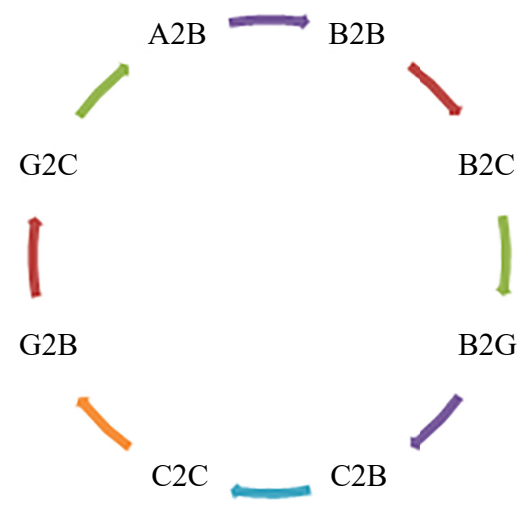

There is a significant reduction in market frictions and significant motivation towards extending world markets at a remarkable pace as e-commerce minimized costs associated with transactions (Eduardsen, 2018). Previous studies have confirmed that e-commerce helps to create new expanded markets, along with scale economies (Mann et al., 2000; Shahdad Nejad and Nakhaie, 2011; Agheli and Hashemi, 2018; Babenko et al., 2019). All the online markets connecting the sellers and buyers are encompassed by e-commerce. For instance, in 2019, the total number of electronic stores reached 25,000 in the Kingdom of Saudi Arabia (KSA); while, it reached 28,000 stores in the first quarter of 2020 with the rise in the COVID-19 crisis. It becomes easier and cheaper for companies to expand as they adopt new markets, which helps them coordinate value chains and manage their company operations. The payments and other finances are facilitated by exchanging possible data through e-commerce (Aydin and Savrul, 2014; Babenko et al., 2019). Figure 2 shows the e-commerce classification, which explains that trade opportunity is created and hosted by the government, business and consumer to make the revenues.

E-commerce has become the first choice of consumers while taking purchasing-related decisions globally, rather than being a secondary option (Nair, 2017; Bhatti et al., 2020). It acts as a double-edged sword as it is beneficial for all the parties, with a major focus on employment sources and consumer's quality of life. However, it has a negative impact on local markets, local production, crime, employment and social/economic indicators. For instance,
Figure 2.

E-commerce classification

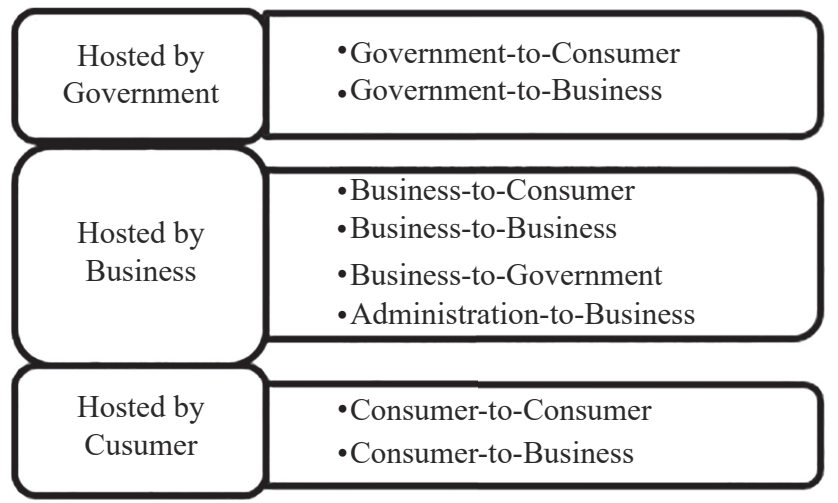


the expected volume of e-commerce in KSA for 2021, including fashion, electronics and media, toys, furniture/appliances and food and personal care, is illustrated in Table 1.

The Saudi government takes several initiatives to develop e-commerce as it is among the significant national transformation program supporting Saudi Vision 2030. The e-commerce system was issued in 2019 that comprised 26 statutory articles. These articles were responsible for preserving the rights of all the parties by protecting e-commerce transactions from deception and fraud. An electronic platform known as Maarouf was launched by the Saudi Ministry of Commerce, which is considered a significant reference for consumers in the online marketplace. There is a need to preserve the rights of e-consumers in KSA so that sellers have the opportunity to expand their market and determine the reliability of electronic stores. This is possible by blocking international and local stores that are not committed to satisfying consumer rights.

An important role is played by the Ministry of Transport and the Ministry of Communications in developing logistic and digital infrastructure for spreading e-commerce. This would also increase the attractiveness of the entrepreneurs towards this growing sector, along with the establishment of social development and human resource system. At present, the main concern of companies is to forecast training competencies and future jobs for fulfilling the requirements of national cadres.

Online shopping has increased with approximately $85 \%$ of the consumers after the outbreak of COVID-19. The majority of the sectors have made most of the COVID-19 crisis; although, setbacks are being experienced in different sectors. E-commerce has made most of the COVID-19 crisis, increasing demand as the consumers avoid going to crowded places and shop online. In light of this, eBay, Amazon and Alibaba have experienced a significant increase in their purchases being done through websites. Recently, Amazon announced that they are out of stock for medical and household supplies due to increased online orders.

Moreover, Amazon also offers employment of new workers to bear the load of increased demand of consumers. Apart from the electronic stores, this density has also been observed on other platforms, including YouTube and Netflix. It is expected that more than 7 million new subscribers would register to Netflix in the latter half of this year.

The COVID-19 pandemic accorded with a substantial reduction in the international prices of crude oil, which more than halved in its market value from the beginning of the year. The oil and gas sector, in the KSA, accounts for approximately $50 \%$ of the gross domestic product (GDP) and 70\% of all export earnings. The adverse demand and supply shock of COVID-19 has been compounded by low oil prices and thus has resulted in a double-digit anticipated reduction of nominal GDP and predicts over $5 \%$ reduction in real GDP, with both oil and nonoil sectors after the first half of 2020. Significant efforts have been demonstrated by the Government of KSA to address the exposure of COVID-19 using a range of well-developed and timely measures for mitigating the effect. More than $7 \%$ of GDP has been invested by the government for alleviating the effect of COVID-19 on the labor market, individuals and the economy. On the contrary, the extent of the COVID-19 pandemic is creating socio-economic imperfections nationwide and globally, in spite of the initiatives of the Government. In addition, it influences every economic sector and every realm of life, with some groups including temporary contractual employees in KSA being certainly influenced and the impacts of reduced remittances influencing their home countries significantly too.

Fashion

Electronics and media

Toys

Furniture/appliances

Food and personal care
Increasing nonoil revenue potentiality 
$\mathrm{JMB}$

1,2

68

Integration of national economies is created in the globalized market via investments, finance and international trade, causing anxiety that captivates the society's direction (Chu et al., 2007). As an economic phenomenon, e-commerce is considered to be associated with international trade consolidation and development. Currently, e-commerce is not only concentrating on revenue, rather, it covers expanding the reciprocal connections among different aspects of community life, such as from religion to finance and from culture to crime. It redefines the role and functions of nation regions, besides it promotes the goods and services connected with the potential product's availability in that particular region (Totonchi and Kakamanshadi, 2011). There is an increase in pre-occupation with distribution policy and marketing components with international societies and extended globalization. In a similar context, the present study aims to analyze and evaluate the potential increase in nonoil revenue through e-commerce in KSA. This paper is diagnostic in nature discussing the socio-economic effects of COVID-19 on the KSA. It further evaluates the socio-economic effects of the COVID-19 pandemic on the Kingdom's non-oil sector through digitalization, e-commerce or digital commerce.

\section{Significance of the study}

There is no doubt that e-commerce faces a similar challenge as all other technology-driven emerging business domains. There is constant pressure to find enough skilled human capital in the workforce (labor) that will accelerate industry developments and control the potential of the business progression. According to the Middle East and North Africa (MENA) report, KSA seems to be the next Center hub for e-commerce investors searching for opportunities beyond Middle Eastern countries (Al-Khouri, 2010).

This paper would further help the Government of KSA, UNDP and other UN agencies to draft and design its certain programmatic responses to this pandemic by determining the limitations in which the government would need their support. Thereby, this paper makes significant efforts in offering policymakers with an insight of the economic strengths of Saudi Arabia, emphasizing fundamental social areas including gender equality, social protection programs, poverty, education and health. This diagnostic paper is keen to address the gaps left by the previous documents and refer back to the policies and assessments for the KSA. The United Nations COVID-19 capacity brief is a complimenting document to the diagnostic paper for the KSA. A list of policy suggestions has been collated within the capacity with respect to 17 sustainable development goals, 23 objectives of the global compact on safe, regular and orderly migration and five developmental pillars for the Kingdom. This tool offers a reference to policymakers and an approach for measuring how appropriately each developmental pillar, GCM and SDGs are being addressed. These sources are not merely addressing issues accounted by the COVID-19 pandemic, but addressing root causes that preceded the existing crisis. The KSA must prefer building back effectively for not delaying the achievement of the Vision 2030.

\section{Literature review \\ National statistics}

The GCC region aims to catch up as penetration of e-commerce quickly is low compared to other developed regions, which indicates massive growth potential. According to the 2018 statistic report by the General authority of Statistics KSA, the largest population is KSA among other Middle Eastern states in the index 35.3 million. This includes 21 million expatriates and 21 million Saudi individuals, who have reached approximately 35 million in 2020 (Table 2). The development of logistics networks is easy as most of the population (84\%) is urbanized. Compared to different countries in the GCC region, KSA outdoes UAE, considering $87.3 \%$ of mobile subscribers and their large shares $(3 \mathrm{G} / 4 \mathrm{G})$. 
The power of human resources in the country cannot be denied, as the main people are strong contributors to a country's success. The increase in national revenue depends on the country's human resources and skilled workers. The survival of the global business is not possible without a group of people doing the right work at the right time. Concerning Table 2 and Figure 3, KSA has more population that leads to excellent human power to establish global business, leading to the overall progress of the national level revenues. A better workforce helps the globalized market or E-commerce trade succeed in career planning and produce better quality products to compete for international trade. According to Global Media Insight, the top 9 most popular e-commerce websites in GCC countries are Souq, Awok, Wadi, Noon, Namshi, Landmarksops, Desertcart, Sharaf DG and Mumzworld (The Oxford Institute for Energy Studies, 2016).

Most of the above e-commerce companies are running their business from the UAE as a central hub; all revenue is claimed by the base country. On April 25, 2016, there was an official unveiling of the country's ambitious plan: "Saudi Vision 2030", after decades of observing the need of diversifying KSA's sources of income. The objective of the vision is to increase the revenue of non-oil products and avoid an oil-dependent economy. In the global oil market, oil prices have fluctuated widely over the years and that oil resources are non-renewable. The sudden drop in oil income or changes in the business infrastructure will create more budget deficiency. The revenue of the oil sector and oil products are major income sources of KSA; therefore, there is a shortage of budget with a reduction in oil products and increase spending (The UAE e-commerce Landscape, 2019) (Table 3).

The difference between the 2016 and 2017 subsequent years is mentioned in the last column of Figure 4. The revenue of 2017 significantly increased in UAE, Bahrain, Oman and

\begin{tabular}{lr}
\hline GCC country & Population \\
\hline Saudi Arabia & $35,340,683$ \\
UAE & $9,991,089$ \\
Bahrain & $1,748,296$ \\
Kuwait & $4,328,550$ \\
Oman & $5,223,375$ \\
Qatar & $2,930,528$
\end{tabular}

Source(s): World Population Review (n.d.)
Increasing nonoil revenue potentiality

Table 2. GCC population

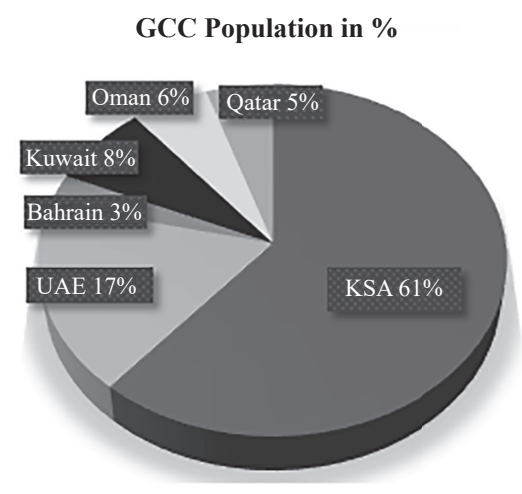

Figure 3.

GCC country population in percentage 
$\underset{1,2}{\mathrm{JMB}}$

Kuwait. KSA's non-oil product export during the year 2017 was not up to the level, and Qatar's revenue uncertainly touched negative value due to the external relationship with other GCC countries.

The combination of eagerness in adopting technology-driven social media/smartphones and digital infrastructure was due to the mass adoption of the Internet in GCC that further encourages e-business solutions. A separate route is taken by the Middle East and North Africa (MENA) region towards digital adoption. In terms of Internet penetration, Middle Eastern regions are ahead of the e-commerce markers prevailing in China and United States (Statistics, 2021).

\section{Role of digitalization in economic development}

It is expected that a nation's economic situation could be changed through the deployment of e-commerce structure and market globalization. E-commerce and globalization affect the economic structure of the majority of the developed nations. The new e-commerce market is referred to as e-economy or digital economy (Dutta and Suresh, 2019). A globalized market is likely to increase flexibility and reduce the communication costs associated with locating activities. It is speculated that international trade has increased due to Internet technology (Al-Khouri, 2010). The process involving the association of financial structures and production with increased cross-border transactions is referred to as globalization (Totonchi and Kakamanshadi, 2011). The governments need to focus on investing more to design a higher level of ICT and reach the global market. Moreover, it is expected that technologies like e-commerce and the Internet are likely to be adopted by global firms for expanding the global market.

\begin{tabular}{lcrr}
\hline & 2016 & 2017 & Variance \\
Country & Export & Export & 1081.3 \\
UAE & 9938.2 & 11019.5 & 279.9 \\
Bahrain & 2482.9 & 2780.8 & 47.6 \\
KSA & 8601.1 & 8648.7 & 914.4 \\
Oman & 2663.5 & 3577.9 & -813.2 \\
Qatar & 1435.0 & 621.8 & 68.1 \\
Kuwait & 914.2 & 982.3 & \\
Source(s): GCC Statistical Center (2021) & &
\end{tabular}

Figure 4.

Non-oil product export difference
Non Oil export variance between 2016 \& 2017

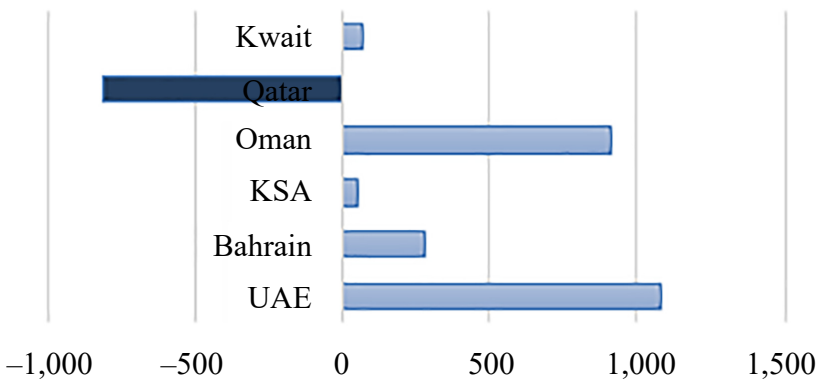


Kraemer et al. (2002) discussed the globalization of business structure, revealing that global and national forces drive the business by using the Internet and e-commerce. Global competitive pressures drive the companies towards increased adoption of e-commerce, resulting in a global networked economy. The study mainly focused on ten countries that were either developed or developing from three major regions of the world and showed that policy and national environmental factors drive the organizations. It is indicated that diffusion is an uneven process across different industries and countries (Kraemer et al., 2002).

Another study by Xu (2010) discussed the satisfaction survey of an e-commerce website for tourism. A satisfaction survey evaluation was proposed for tourism using e-commerce. There was the establishment of a satisfaction evaluation index for the user for tourism website, and pairwise comparisons were made to evaluate discriminant matric following weights of evaluation indexes. The experimental analysis helped depict the result of a user's satisfaction evaluation concerning a certain e-commerce website about tourism. The evaluation results revealed that user's evaluation concerning e-commerce for tourism was satisfactory $(\mathrm{Xu}, 2010)$.

The importance of technology in e-commerce was investigated by Babenko et al. (2019). It is believed that the progress and impact of technology-related devices is an important factor that affects the customs and traditions in different countries to use technology. Among the factors affecting the development and application of information technology, cultural disputes play an important role. The active companies need to increase their familiarity with various business-related negotiations and deals considering the growing nature of electronic commerce and confrontation with national and cultural borders. The main aim of this study was to reveal the important role of nature affecting the development of international trade and e-commerce (Babenko et al., 2019). It has been shown that there is a significant impact of e-commerce on people as they try to get familiar with the problems and issues related to e-commerce.

Totonchi and Manshady (2012) focused on individual company involvement, opportunity and benefits towards globalization and setting up the ICT structure for the individual company. Research findings suggest that global business supports the domestic market and increase competitiveness. It is also suggested that upgrading the domestic industry to a global level through e-commerce will give more advantages than the domestic market. Moreover, establishing an e-commerce business is very easy with the help of ICT structure and setting up the website to offer products and services. E-commerce business is a virtual environment business to get more financial support from the global country. The domestic market has some business restrictions, such as no identical product, fixed place room, local knowledge, strong brand name, transport services, etc. Therefore, the reasons mentioned above are likely to create the B2B and B2C business (Totonchi and Manshady, 2012).

Aydin and Savrul (2014) discussed the significance of globalization. The growth of information communication industries and their different services would provide more opportunity and investment to enable new markets. The research study discussed the mutual relationship between buyer and seller, accessing new raw materials, resources, etc. However, the relation's direction variates concerning the substructure of communication and level of technology within a region. Globalization affecting e-commerce creates an opposite situation; for instance, the relationship between globalization and e-commerce is complicated. In a broader view, productivity, employment patterns and industry structure are significantly affected by e-commerce (Aydin and Savrul, 2014).

\section{Potentials in commerce market}

There is an excellent opportunity for KSA to make global industry considering the transformation of this region after Saudi Vision 2030. Along with young people, women 
$\mathrm{JMB}$

1,2

would be seen leading the booming business, and this would be considered an aggressive development. KSA is considered the best choice to expand e-commerce trade compared to MENA and GCC region (AlArfaj et al., 2019). The current reforms in KSA, including the explosion of the entertainment industry, women driving and issuing licenses for sports outlets, have affected every home (Sheikh et al., 2017). The chance of creating opportunities for youth and motivating women to do online business is also booming. In KSA, the domestic trade is under the supervision of women as they are being appointed as front-of-line sales and business representatives and store managers (Altameem and Almakki, 2017).

Every country is gifted with some specific resources. Suppose any country aims to improve or develop a national economy, its required different resources from various countries. Some countries have a high infrastructure, workforce and educational background, while others do not. Encouraging and promoting international business benefits will increase the national revenue and provide better services and opportunities to the domestic people (Jin et al., 2018). Exporting the benefit of excessive resources would increase national revenue, employment opportunity and foreign exchange. Simultaneously, it is beneficial for the consumers to get products with higher quality at a lesser price than domestic products in countries importing those specific goods (Aqlan, 2020). International or global markets provide an opportunity to exchange goods and services between countries with better and competitive prices (Khotamov and Ismoilov, 2020). There will not be enough money to import goods that a country typically buys without foreign currency earned by exporters. Some foreign currency is earned from investments made abroad, inward investments and remittances by the expatriate; however, these are nowhere near enough to pay for all the foreign goods and services consumed by a typical modern economy.

One of the main reasons importing goods by wealthy countries like KSA is the global economy's benefit. It is impossible to avoid importing goods from our daily lives, such as medicine, foods, smartphones, etc. The digital world also relies on imports to build supportable goods such as cables, microchips and oil used to produce domestic goods (D Al-Tayyar et al., 2021). The domestic economy is likely to be weakened due to increased product imports because of an increase in unemployment and budget deficit. It is important to stabilize the domestic economy by maintaining its balance via international trade. The international export shows their reliance on developing economic countries for staying afloat.

Employment opportunities and additional opportunities for growing business and domestic and international markets are considered the main advantages of international business segment establishment through e-commerce (Nair, 2017). The maximum revenue of KSA depends on oil-related products. There is no fixed price for oil products, and it fluctuates all the time, affecting the domestic economy of KSA (Figure 5). The countries involved in global trade can still benefit from their worldwide customers, even if the local economy suffers. The benefits of international trade can be elevated by trading with countries having stronger currency than local currency. Generally, the revenue is increased, and the local economy is boosted by exporting goods generally. Therefore, it is essential to bring the international business policies and procedures to raise the KSA income and employment opportunity to compete with the other nations.

\section{The global market}

There was an increased establishment of electronic stores since $2020(171 \%)$ as >36,000 electronic stores have been established over the last year. Opportunities are provided to build projects as there is an increase in the establishment of electronic stores. Social networking sites are being accessed by $>97 \%$ of the Internet users in KSA since 2019 . According to statistics of e-commerce in KSA for 2019, the rate of e-commerce revenues reached $\$ 4.930$ billion, with an Internet penetration rate of $89.5 \%$ and Internet use of $95.7 \%$. Considering the 


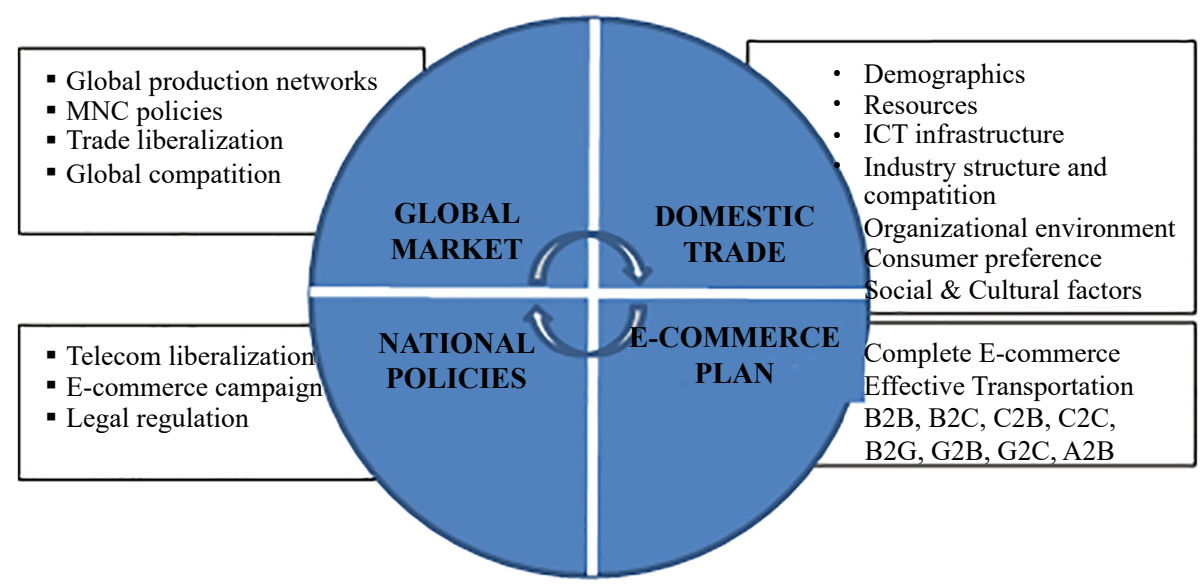

Increasing nonoil revenue potentiality

global trade and investment, the volume of the e-commerce market was approximately 30 trillion dollars. In KSA, the logistic and e-commerce market volume reached 21 billion dollars, equal to 80 billion riyals.

The worldwide spread of the COVID-19 demonstrates the importance of e-commerce and telemarketing in saving lives and ensuring their safety (Lin et al., 2020). This situation has generated questions about dealing with these trade and delivery businesses and how e-commerce fits into the KSA's 2030 goal. Moreover, a large percentage $(60 \%)$ of the Saudi youth contributed towards the emergence of the digital consumer in KSA.

There is evidence about the interest of KSA in e-commerce for achieving the retail sector's development as a strategic goal based on the National Transformation Program 2020 (Mitchell and Alfuraih, 2018). The regulation of e-commerce is based on some serious steps, and legal infrastructures as an e-commerce system are issued. The e-commerce system applies to everyone practicing trade-in KSA. The parties get involved in a sector by promoting e-commerce. There is an increase in transaction reliability, protecting consumers from fraud and deception, ensuring that their data are not misused and allowing a commercial register to engage in e-commerce subject to certain controls (Kwilinski et al., 2019). By encouraging e-commerce, the stakeholders involved in the business may communicate more effectively. It also requires service providers to reveal their commercial data, supervise and control the electronic commercial advertising market to prevent fraud and establish supervisory committees to investigate violations of the system's regulations. In addition, an e-commerce council has been created, which is primarily responsible for establishing e-commerce policies. The Council's recommendations are implemented through legislation and consultation with interested parties such as the Ministry of Trade and Investment.

\section{Global production networks}

An important determinant of increased national income is participation in global production networks. There are two categories, multi-domestic and global integration, involved in the global production network. Multi domestic-related service is independent, where the market operation takes place (Obashi and Kimura, 2021). The globally integrated complex product involves each component of the supply chain that directly affects the final product's quality and cost. The four factors being concerned by global production are; regional production, centralized global production, vertical transnational integration and regional specialization (Li, 2021). 
$\mathrm{JMB}$
1,2

74

MNC policies

Multinational companies are also known as global enterprises as they operate worldwide. Their activities are under the control of a parent company. Selling of services and products by the MNC required global management. MNC company policies should be suited to the national law of the individual countries, where they operate with proper maintenance of business confidentiality (Momin, 2020). The growth of the domestic business has boomed in KSA after the implementation of new procedures and policies in the last few years. The list of top manufacturing companies in the GCC region is shown in Figure 6. KSA possesses a wide range of human resources, minerals, fisheries and oil resources, and it can offer more multinational companies to increase non-oil revenue. Setting up multinational companies in their soil will encourage the local entrepreneurs to support their community, rather than importing from countries involves in mass manufacturing (Saini and Kumar, 2020).

\section{Trade liberalization}

The free exchange of goods without any restriction or barriers between the countries is called trade liberalization. There are two types of trade restrictions implemented by a country; tariffs and non-tariff barriers. Surcharges and duties are examples of tariff barriers; while, quota and licensing rules are examples of non-tariff barriers (Wulansaria and Parwantob, 2020). It is claimed by trade liberalization that the implementation of certain policies would increase unemployment as cheaper goods will flood the domestic market. Further, it is believed that these goods could be less safe and of low quality than domestic products undergoing rigorous quality and safety checks (Soundararajan, 2018). The supporter of trade liberalization claims that trade liberation increases efficiency, boosts economic growth and decreases consumer cost.

\section{The national environment}

There is a need for effective institutional frameworks and environmental policies at regional, national, local and international levels. The national environment consists of many factors such as economic and financial resources, ICT infrastructure, organization environment, industry infrastructure, demographic and consumer choices, etc. Countries are undertaking a wide range of environment-related factors under the framework of the World Trade Organization framework, which includes negotiations with tariff reductions for environmental services and goods.

\section{NO. OF TOP MANUFACTURING COMPANIES IN GCC}

Figure 6.

GCC manufacturing companies
161

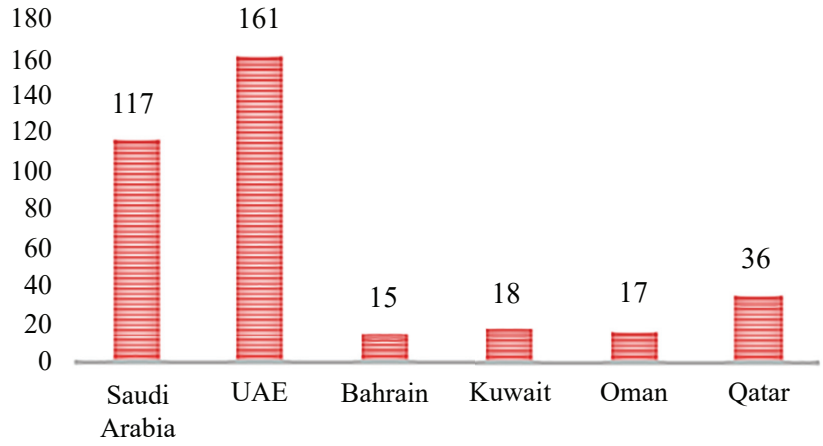

Source(s): Gulf Talent, 2021 
Demographic factors

The country demographics indirectly affect the e-commerce development either by constraining the conditions or enabling them. These demographics mainly include income, age, geography and the major impact of education, gender, employment status, household size, occupation and race. These variables can affect the setting up of international business. Therefore, it is significant to consider buying power and growing market and the viable group as well. People's buying preferences, education, social media penetration and employment status are considerable points of demographic structure.

Since the last decade, KSA is considered the second largest Arab state, and its Gross National Product (GDP) has increased by about 520 billion USD. This increase corresponds to a positive import-export trade balance per the 2017 statistic report by Gulf Country Council (Figure 7). As shown in Figures 8 and 9, the export revenue of KSA is 1.5 times higher than its import revenue. It is shown that KSA's population is approximately 34.14 million, according to the World Bank's data. It comprises $61 \%$ of the entire GCC region, revealing that KSA shows a growth rate of $1.93 \%$ since 2018 with an estimated 22.55 million population.

\section{Economic and financial resources}

There is a direct and significant impact of financial and economic resources as drivers of e-commerce. E-commerce sales are driven by the wealth that is considered as a strong and important individual factor. At present, regional recessions, e-commerce sales and
Increasing nonoil revenue potentiality

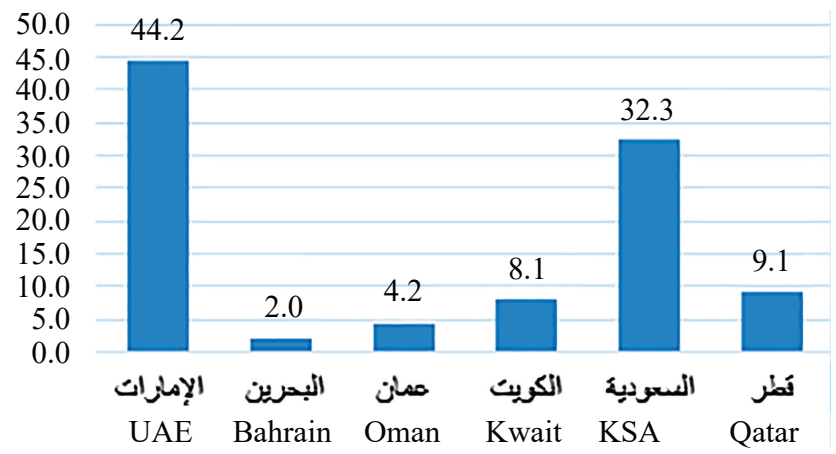

Source(s): GCC Statistical Center, 2021

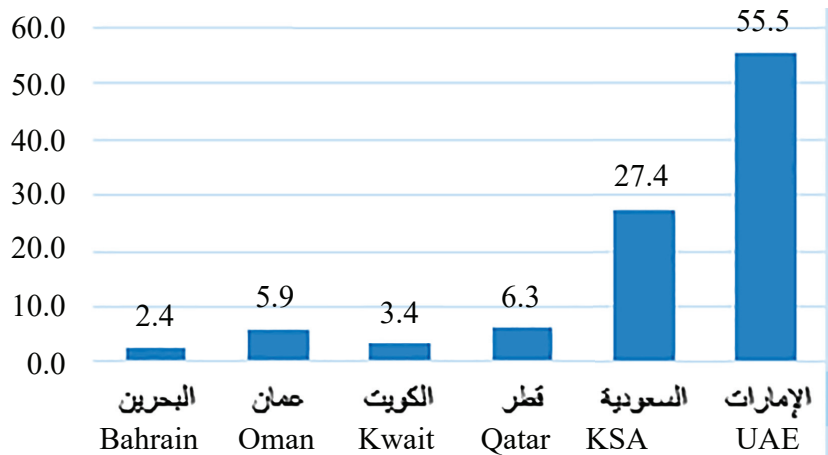

Figure 8

Total imports of GCC countries in 2020

Source(s): GCC Statistical Center, 2021

Figure 7.

Percentage distribution of trade balance in GCC 2020 
$\underset{1,2}{\mathrm{JMB}}$

76

Figure 9.

Total exports of GCC countries in 2020

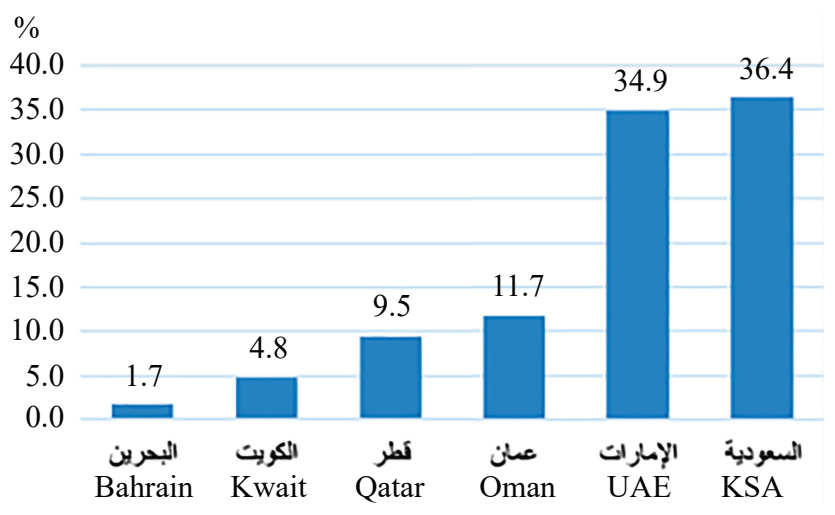

Source(s): GCC Statistical Center, 2021

slowdowns in the global economy have affected most countries worldwide (Salem and Nor, 2020). Another driver of e-commerce across countries is financial resources like venture capital supporting startups and online businesses. Another financial factor that drives e-commerce is the availability of online payment procedures such as stored value cards, money orders, cash-on-delivery, debit cards and wireless payment (Batwa and Alamoudi, 2019). Economic diversification, enhancement in employment opportunities in the private sector (especially for young individuals and human) and fiscal consolidation need support in KSA, specifically.

\section{Information infrastructure}

E-commerce dispersion is aided by a broadly available and inexpensive information infrastructure. The breadth of technologies and the level of coverage are both availability factors. The high penetration of numerous technologies enables e-commerce since more channels are accessible for doing it (Alshehri and Meziane, 2017). The new company structure's strategy and procedures must be restructured to respond appropriately to these possibilities and challenges. Governments and businesses embrace new technology to expand their goods and enter the worldwide market due to growing competition.

\section{Industry structure}

The industrial structure is likely to impact e-commerce adoption since certain industries are likely to be leaders while others lag. Finance, ICT, wholesale, retail, electronics manufacturing and automobile manufacture are all general businesses throughout nations (Aqlan, 2020). Other important industries are those in which each country has a competitive edge, such as healthcare, agriculture and shipping in Denmark, or freight forwarding and publishing in Singapore. Overall, the industries that drive e-commerce are those that are informationintensive and globally competitive.

\section{Organizational environment}

The key factor affecting B2B e-commerce is the organizational environment. The increased costs associated with IT, lack of integrated information systems and security concerns restrict the organizational readiness for e-commerce in most countries. Local rivalry and industry pressure might be crucial drivers of e-commerce adoption in the workplace; however, such competitive pressure is still minimal at this early stage of e-commerce growth. 
Entrepreneurial company culture is another facet of the organizational environment that drives B2B e-commerce. The organizational and legal climate in KSA should promote entrepreneurship by making bankruptcy financially viable, allowing unsuccessful entrepreneurs to start again without being stigmatized.

\section{Consumer preferences}

Consumer attitudes and preferences are fundamentally influencing e-commerce adoption. Consumers have noticed throughout the world, and there are great hopes and expectations for beneficial economic and social outcomes. Customers have substantial misgivings about making purchases online; although, the Internet's buzz may encourage users to use it. Lack of trust and privacy concerns in giving up credit card numbers and other personal information, resistance to using credit cards, shopping habits and preferences for in-store shopping and product inspection contribute to consumer hesitation. The language barriers also play a role due to the prominence of linguistic material on the Internet, specifically among non-English speaking and non-Arabic speaking customers. Beyond language, there is a clear preference for local content in all nations.

\section{National policy}

Making national policies around e-commerce and globalization is a highly analytical and political process involving diverse forces. The desire of citizens or society to form national policy is the starting point. It is a proposal or demands made by the different groups or society to take action by the political system to save the domestic environment and fulfill the society's requirements.

The national policy considers many strategy issues such as data privacy, consumer protection, domestic market protection, environmental protection, etc. Investors, manufacturers, MSMEs, merchants, merchants, startups and consumers all have interests considered while making policy. Along with the 'Saudi Vision 2030' current policies, the national e-commerce Policy intends to build a framework for a comprehensive expansion of the e-commerce industry.

\section{Telecommunications liberalization}

Government support and funds can increase universal service and create the ICT infrastructure essential for overall economic growth. Telecom liberalization is a significant factor of the country that will help to improve the economic potentiality (Wulansaria and Parwantob, 2020). E-commerce is fueled by general market liberalization, which opens up markets to competition, resulting in higher-quality items and services at cheaper costs. In competitive marketplaces, businesses are encouraged to use e-commerce to improve efficiency and service (Gur, 2021).

The Internet provides access to communications, information and opportunity for individuals and society. It would be impossible for most outsourcing firms to run without Internet technology like VoIP, digital documents and e-commerce. Table 4 and Figure 10 show the percentage of Internet users from 2011. The Internet penetration will upsurge outstanding healthcare services, medicine, maternal advice, tips/tricks, access to local government, education, retail and wholesale trade, etc. Hence, it is a tremendous opening to begin the global market in KSA.

\section{E-commerce promotion}

Developing innovative e-commerce promotion ideas can be tough. Although government promotion aids e-commerce, it does not appear to impact economic or telecom liberalization 
directly (Arrafi and Ghabban, 2021). Government promotion takes many forms in different countries. Still, the most prevalent sectors include IT and e-commerce promotion in enterprises, particularly SMEs, by providing technical help, training and money for IT usage. In several nations, initiatives to increase government use of e-commerce for e-procurement and e-government have been launched (Malibari, 2020). Offering global industry incentives and specific regulations and procedures is a powerful way to increase auxiliary traffic, attract new entrepreneurs and boost income. Best of all, these promotions may be utilized to entice new businesses to become loyal and invest more frequently.

\section{E-commerce legislation}

The regulations specify the information, and the origin country assures global industry and its global customers while exchanging goods and services online. Between nations, no uniform policy or comprehensive regulation on e-commerce has been formed. Various nations have concentrated on different concerns, with the law on digital signatures, privacy, consumer

\begin{tabular}{lc}
\hline Year & Internet users in \% \\
\hline 2011 & 47.50 \\
2012 & 54.00 \\
2013 & 60.50 \\
2014 & 64.71 \\
2015 & 69.62 \\
2016 & 74.88 \\
2017 & 82.12 \\
2018 & 93.31 \\
Source(s): ITU (2021) &
\end{tabular}

Percentage of internet users in KSA

Figure 10.

Percentage of Internet user

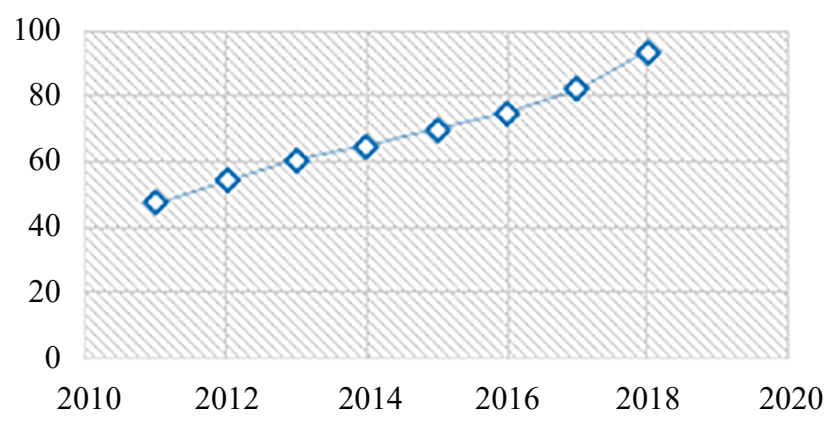

Types of E-commerce law No of country implemented $(\%)$

E-transactions laws

Table 5.

Consumer protection laws 79

Privacy laws

Cybercrime laws

52

58

72

Source(s): UNCTAD (n.d.) 
protection, copyright, intellectual property and content control is among the most prominent (Table 5). UNCTAD assists policymakers and legislators at the national and regional levels better understand the fundamental challenges driving e-commerce. The main issues encountered by e-commerce are; data privacy, computer crime, competition, information security, electronic transactions, consumer protection, intellectual property and taxation.

\section{E-commerce, COVID-19 and non-oil GDP}

Saudi's Vision 2030 was established in 2016 for increasing the revenue sources for the Kingdom, which relied majorly on oil revenues. Majority of the Saudi Arabia's Vision 2030 goals were fulfilled, in a short period, by introducing different advancements and sectors. The economy of country flourished and became less reliant on oil profits. The non-oil revenues of Saudi Arabia have elevated by $3.3 \%$ in 2019 . The general authority of entertainment is the most dominant of these newly founded sectors, accounting profits of 2.69 billion Saudi riyals in the second quarter of 2019.

The General Entertainment Authority serves for enhancing the quality of life by cooperating with different private and governmental sectors in the Kingdom with the instigation of hosting concerts, music festivals, comedy clubs, bazaars, shows and events. With the Vision 2030, Saudi Arabia has successfully invested to reshape the country as a hub for tourism and business, for drawing millions of tourists a year. The recent progression of the Saudi Ministry of Culture, irrespective to the entertainment authority, has further led to an ever-increasing number of social, international, domestic and cultural events within Saudi Arabia. New developments have further emerged in public spaces such as coffee shops, gyms, parks, restaurants and shopping centers. The initiatives of the entertainment industries are having positive effects on the living standards in the Kingdom, which has become more social, active and lively. On the contrary, realms of life have been influenced majorly because of the COVID-19 crisis globally.

A number of safety measures, in Saudi Arabia, have been integrated against the virus, some of which encompass the closing down of shopping centers and malls, the establishment of curfews, the cancellation of schools and universities and banning of gatherings. These precautions were important for controlling the exposure of the disease, accounting the number of confirmed cases to radically elevate daily. A significant role has been played by oil revenues in 2020 as compared to year 2019. COVID-19 further influenced non-oil dependent revenues because there were bans on public enforcements and gatherings that stressed individuals for staying at home, entertainment and tourism sectors were urged to halt.

The government of Saudi Arabia has anticipated that $42 \%$ of its non-oil economy will generate taxes on goods and services in 2019. Taxes on capital gains, income and profits are anticipated to yield approximately $5 \%$ of revenue. It is assumed that the elevation in highinvestment has been an important support factor in non-oil activity in 2020, with more significant growth with larger projects.

\section{Discussion and recommendations}

Globalization provides the opportunity to the customer; for instance, there are multiple payment options to buy the goods and services from the global market with PayPal, STC pay, Square, Samsung Pay, Apple Pay, Visa Checkout, etc. These multiple payment options will increase the domestic sale, and international sales will increase the national revenue. Next, the permitting of traveler visas comes within the KSA's plan to create a million jobs, and it may be expected to reach 100 million travelers by the year 2030. At present, KSA's national policies on tourism and inviting global investors will increase the national income and creates incredible domestic job opportunities.
Increasing nonoil revenue potentiality 
$\mathrm{JMB}$

1,2

80

Inviting international investors may expose the country to new ideas, management methods, marketing strategies and competing methods, which can help the country to improve its economic standing on a worldwide scale. Exploring domestic products helps a company to expand its market beyond the confines of a small, oversaturated national market. There is no need for a country to export unless it intends to gain profit. Oil resource exports are no longer completely reliant on domestic and international market sales. As a result, if economic conditions deteriorate, the impact on national revenue may be mitigated if a country's other businesses can grow into overseas markets. It is also recommended that a country not grow overly reliant on a single export market since this might leave them exposed to national economic swings.

\section{Conclusion}

The study concluded many effective strategic plans to implement effective global business in KSA through digital commerce. With the current economic recession on the global market, it is important to increase non-oil production to gain national revenue and stabilize the economy. Moreover, it is significant to restructure KSA's national policies and procedures to achieve Saudi Vision 2030. The proposed strategic plan has several strengths. Firstly, it can evaluate different types of e-commerce opportunities to conduct in the domestic and international market. Next, it revealed current national policies and procedures. In addition, the study also analyzed the international e-commerce market and domestic market opportunities. The framework design in this study is based on a perusing approach, not an analytical approach. Thus, future research should focus on developing another perusing based on an analytical strategy. The proposed conceptual framework has provided specific criteria to measure and suggest the minimization of barriers to start a global company to increasing non-oil income in KSA. However, the full range of measurement is not created until installing the new economic policies and procedures. Global traders look for feasible economic policies and procedures and a healthy political environment to provide a long-term business environment. Finally, platforms of e-commerce and the global market are still in the stage of evolution. Dominant players, such as the US, China, the UK and Europe, continually develop and bring new policies and procedures to make more revenue and strengthen their economy. In conclusion, it is stated that the conceptual framework is capable of evaluating the global market and e-commerce. Furthermore, it is expected that KSA's measures to facilitate licensing and activate inexpensive e-commerce enablers help this sector expand from strength to strength.

\section{References}

Agheli, L. and Hashemi, S. (2018), "Impact of information and communication technology on transport among the selected Middle East Countries", Journal of Economic Cooperation and Development, Vol. 39 No. 1, pp. 1-17.

Al-Khouri, A.M. (2010), "The challenge of identity in a changing world: the case of GCC countries", Conference Proceedings: the 21st-Century Gulf: The Challenge of Identity.

AlArfaj, A., Solaiman, E. and Marshall, L. (2019), Social Media and E-Commerce in the Kingdom of Saudi Arabia-Trends and Future Directions, CHI-ArabHCI.

Alshehri, H. and Meziane, F. (2017), "Current state on internet growth and usage in Saudi Arabia and its ability to support e-commerce development", Journal of Advanced Management Science, Vol. 5 No. 2, pp. 127-132.

Altameem, E. and Almakki, R. (2017), "E-Commerce implementation: a critical review”, International Journal of Computing, Vol. 6 No. 2, pp. 12-19. 
Aqlan, M.A.A. (2020), "Research on the status quo and countermeasures of cross-border E-commerce development in Arab countries", Open Journal of Business and Management, Vol. 8 No. 4, pp. 1536-1542.

Arrafi, I.M. and Ghabban, F.M. (2021), "Impulse buying model for business-to-consumer E-commerce in Saudi Arabia", iBusiness, Vol. 13 No. 2, pp. 81-102.

Aydın, E. and Savrul, B.K. (2014), "The relationship between globalization and e-commerce: Turkish case", Procedia-Social and Behavioral Sciences, Vol. 150, pp. 1267-1276, doi: 10.1016/j.sbspro. 2014.09.143.

Babenko, V., Kulczyk, Z., Perevosova, I., Syniavska, O. and Davydova, O. (2019), "Factors of the development of international e-commerce under the conditions of globalization", SHS Web of Conferences, Vol. 65, EDP Sciences, p. 04016, doi: 10.1051/shsconf/20196504016.

Batwa, A. and Alamoudi, R.H. (2019), "Designing and deploying an E-business model for small and medium-sized enterprises in Saudi Arabia”, Journal of Economics and Business, Vol. 2 No. 4, pp. 1129-1155.

Bhatti, A., Akram, H., Basit, H.M., Khan, A.U., Raza, S.M. and Naqvi, M.B. (2020), "E-commerce trends during COVID-19 Pandemic", International Journal of Future Generation Communication and Networking, Vol. 13 No. 2, pp. 1449-1452.

Chu, S.C., Leung, L.C., Van Hui, Y. and Cheung, W. (2007), "Evolution of e-commerce Web sites: a conceptual framework and a longitudinal study", Information and Management, Vol. 44 No. 2, pp. 154-164, doi: 10.1016/j.im.2006.11.003.

D Al-Tayyar, R.S., Abdullah, A.R.B., Abd Rahman, A. and Ali, M.H. (2021), "Challenges and obstacles facing SMEs in the adoption of e-commerce in developing countries; a case of Saudi Arabia", Studies of Applied Economics, Vol. 39 No. 4, pp. 1-11.

Dutta, T. and Suresh, A. (2019), "Economics of globalisation or globalisation of economics", available at: SSRN 3397592, doi: 10.2139/ssrn.3397592.

Eduardsen, J. (2018), "Internationalisation through digitalisation: the impact of E-commerce usage on internationalisation in small-and medium-sized firms", International Business in the Information and Digital Age, Emerald Publishing.

GCC Statistical Center (2021), available at: https://gccstat.org/en/contact.

Gulf Talent (2021), “Top manufacturing companies”, available at: https:/www.gulftalent.com/ manufacturing-companies.

Gur, B.A. (2021), "Restrictions on trade in telecommunications: WTO's cybersecurity conundrum", Journal of World Trade, Vol. 55 No. 3, pp. 477-498.

ITU (2021), "Committed to connecting the world”, available at: https://www.itu.int/en/Pages/ default.aspx.

Jin, B., Almousa, M.O. and Kim, N. (2018), "Retailing amid regulation and religion: the unique cultural challenges and opportunities facing market ventures in Saudi Arabia”, Journal of Cultural Marketing Strategy, Vol. 3 No. 1, pp. 70-81.

Khotamov, I. and Ismoilov, A. (2020), "Is estimating and forecasting trends of global export and import of goods in international markets", Scientific Research Archive, Vol. 1 No. 5, available at: https://tsue.scienceweb.uz/index.php/archive/article/view/1355.

Kraemer, K., Gibbs, J. and Dedrick, J. (2002), "Environment and policy factors shaping e-commerce diffusion: a cross-country comparison”, ICIS 2002 Proceedings, p. 30, doi: 10.1080/ 01972240309472.

Kwilinski, A., Volynets, R., Berdnik, I., Holovko, M. and Berzin, P. (2019), "E-commerce: concept and legal regulation in modern economic conditions", Journal of Legal, Ethical and Regulatory Issues, Vol. 22, pp. 1-6.

Li, Y. (2021), Research on E-Commerce Purchasing Model in Crude Oil Trade, Scientific Programming. 
$\mathrm{JMB}$

1,2

Lin, L., Junyan, Z. and Liping, W. (2010), “The evaluation of China's insurance e-commerce website running based on entropy Theory”, 2010 International Conference on Computer Design and Applications, IEEE, Vol. 2, pp. V2-V126, doi: 10.1109/iccda.2010.5541147.

Lin, J., Li, L., Luo, X.R. and Benitez, J. (2020), "How do agribusinesses thrive through complexity? The pivotal role of e-commerce capability and business agility", Decision Support Systems, Vol. 135, p. 113342, doi: 10.1016/j.dss.2020.113342.

Malibari, M.A. (2020), "The role of E-commerce platforms in enhancing competitiveness "an exploratory study on SMEs in Saudi Arabia”, Egyptian Computer Science Journal, Vol. 44 No. 1.

Mann, C.L., Eckert, S.E. and Knight, S.C. (2000), Global Electronic Commerce: A Policy Primer, Peterson Institute for International Economics.

Mitchell, B. and Alfuraih, A. (2018), "The Kingdom of Saudi Arabia: achieving the aspirations of the national transformation program 2020 and Saudi vision 2030 through education”, Journal of Education and Development, Vol. 2 No. 3, p. 36, doi: 10.20849/jed.v2i3.526.

Momin, S. (2020), "E-commerce acceptance and implementation among consumers in the UAE: an opportunity to build human capital for future jobs in technology and marketing", Human Capital in the Middle East, Palgrave Macmillan, Cham, pp. 253-272.

Nair, K.S. (2017), "Impact of e-commerce on global business and opportunities-a conceptual study", International Journal of Industrial Engineering and Management Research, Vol. 2 No. 2, pp. 324-336.

Obashi, A. and Kimura, F. (2021), "New developments in international production networks: impact of digital technologies”, Asian Economic Journal, Vol. 35 No. 2, pp. 115-141, doi: 10.1111/ asej.12240.

Rosen, A. (2000), "The e-commerce question and answer book: a survival guide for business managers", Language, Vol. 14 No. 210p, p. $23 \mathrm{~cm}$.

Saini, J.S. and Kumar, N. (2020), "Issues pertaining to growth of digital economy: an arduous challenge before CCI", Journal of Public Affairs, Vol. 20 No. 4, p. e2301.

Salem, M.A. and Nor, K.M. (2020), "The effect of COVID-19 on consumer behaviour in Saudi Arabia: switching from brick-and-mortar stores to E-Commerce", International Journal of Scientific and Technology Research, Vol. 9 No. 07, pp. 15-28.

Shahdad Nejad, N. and Nakhaie, H. (2011), "The role of culture in the development of electronic commerce", 3rd International Conference on Information and Financial Engineering, Singapore, Vol. 12, pp. 513-517.

Sheikh, Z., Islam, T., Rana, S., Hameed, Z. and Saeed, U. (2017), "Acceptance of social commerce framework in Saudi Arabia”, Telematics and Informatics, Vol. 34 No. 8, pp. 1693-1708.

Soundararajan, G. (2018), "Impact of E-commerce on global business environment: a conceptual study focus on Middle East", Eurasian Journal of Analytical Chemistry, Vol. 13, pp. 96-98.

Statistics (2021), available at: https://www.itu.int/en/ITU-D/Statistics/Documents/statistics/2019/ Individuals_Internet_2000-2018_Jun2019.xls (accessed 23 September 2019).

The Oxford Institute for Energy Studies (2016), "Saudi Arabia's vision 2030, oil policy and the evolution of the Energy sector", available at: https://www.oxfordenergy.org/wpcms/wp-content/ uploads/2016/07/Saudi-Arabias-Vision-2030-Oil-Policy-and-the-Evolution-of-the-EnergySector.pdf.

The UAE e-commerce Landscape (2019), available at: https://ae.visamiddleeast.com/dam/VCOM/ regional/cemea/unitedarabemirates/home-page/documents/visa-white-paper-v4.pdf.

Totonchi, J. and Kakamanshadi, G. (2011), "Globalization and e-commerce", 2nd International Conference on Networking and Information Technology, pp. 270-276. 
Totonchi, J. and Manshady, K. (2012), "Relationship between globalization and e-commerce", Increasing nonInternational Journal of e-Education, e-Business, e-Management and e-Learning, Vol. 2 No. 1, p. 83.

UNCTAD (n.d), "Statistics", available at: https:/unctad.org/statistics.

World Population Review (n.d), "GCC countries", available at: https://worldpopulationreview.com/ country-rankings/gcc-countries.

Wulansaria, I.Y. and Parwantob, N.B. (2020), "Asian e-commerce engages global trade openness: the role of information and communications technology, social, and security indicators", International Journal of Innovation, Creativity and Change, Vol. 11 No. 12, pp. 110-136.

$\mathrm{Xu}, \mathrm{A}$. (2010), "Satisfaction evaluation of user of e-commerce for tourism based on analytic hierarchic process", 2010 The 2nd International Conference on Computer and Automation Engineering (ICCAE), IEEE, Vol. 4, pp. 91-94, doi: 10.1109/iccae.2010.5451777.

\section{Corresponding author}

Saeed Q. Al-Khalidi Al-Maliki can be contacted at: salkhalidi@kku.edu.sa

For instructions on how to order reprints of this article, please visit our website: 